\title{
Interpretation of Collectivism Thoughts Contained in Mathematical Theory
}

\author{
Wenbing $\mathrm{Wu}$, Jinquan Xiong \\ Nanchang Normal University, Nanchang, China \\ Email: wwbysq@fjnu.edu.cn
}

How to cite this paper: Wu, W. B., \& Xiong, J. Q. (2021). Interpretation of Collectivism Thoughts Contained in Mathematical Theory. Creative Education, 12, 28062810.

https://doi.org/10.4236/ce.2021.1212207

Received: November 6, 2021

Accepted: December 13, 2021

Published: December 16, 2021

Copyright $\odot 2021$ by author(s) and Scientific Research Publishing Inc. This work is licensed under the Creative Commons Attribution International License (CC BY 4.0).

http://creativecommons.org/licenses/by/4.0/

(c) (i) Open Access

\begin{abstract}
The mission of higher education is to train senior professionals with a sense of social responsibility, innovative spirit and practical ability. Higher education should regard the effectiveness of cultivating people as the fundamental standard for testing all the work of colleges and universities, insist on the unity of knowledge transfer and value guidance, and the unity of explicit education and implicit education, and fully explore the humanistic spirit contained in various courses and teaching methods. In this paper, by combining the change of correlation coefficient in mathematical statistics with collectivism, it pays attention to cultivating students' humanistic quality and collectivism. The teaching effect shows that this teaching method has a certain positive effect on cultivating qualified talents that meet the needs of society.
\end{abstract}

\section{Keywords}

Higher Education, Collectivism, Correlation Coefficient, Random Variables

\section{Introduction}

Humanistic spirit is a kind of universal human self-care, manifested in the maintenance, pursuit and concern of human dignity, value, and destiny, high cherishment of various spiritual and cultural phenomena left over from mankind, and a comprehensive development of ideal personality. The humanity is a knowledge education system that focuses on the humanistic spirit, and it focuses on the human value and spiritual performance. In a sense, the reason why people are the spirit of all things lies in their humanities and their own unique spiritual culture (Zhu, 2002; Zhang, Wang, Li et al., 2005).

In short, the humanistic spirit is the people-oriented spirit. It emphasizes the spirit of starting from human beings and taking human as the destination. It is 
an ideological attitude that attaches great importance to human value and dignity.

\section{Collectivism}

Collectivism is an ideological theory that advocates that individuals are subordinate to society and that individual interests should be subordinate to the interests of the group, nation, and the country. It is a spirit. The highest standard is that all speech and actions conform to the collective interests of the people.

Collectivism is a philosophical, political, religious, economic, or social point of view that emphasizes the interdependence of everyone. Collectivism is a basic cultural element, anti-individualism exists in human nature, and in some cases it emphasizes the importance of the priority and cohesion of organizational goals to personal goals. Collectivists usually focus on the community, society, or country. It is used as an element throughout many different economic and educational philosophies. In practice, all human societies contain nelements of individualism and collectivism. Collectivism can be divided into horizontal collectivism and vertical collectivism. Horizontal collectivism emphasizes collective decision-making among relatively equal individuals, so it is usually based on decentralization. Vertical collectivism is based on the consistency of the hierarchical structure of power and moral culture, so it is based on the concentration of power. Cooperative enterprise is an example of horizontal collectivism, while military hierarchy is an example of vertical collectivism (Oyserman, Coon, \& Kemmelmeier, 2002; Boone, Meng, \& Velden, 1995).

\section{Correlation Coefficient}

Correlation coefficient is the first statistical indicator designed by statistician Carl Pearson (Weiß, 2018; Dillon, 2014; Robertson, 1959; Filliben, 1975; Mu, Liu et al., 2018; Xiong, Liang, Wan et al., 2018). It is a measure of the degree of linear correlation between variables. It is generally represented by the letter $r$. Due to different research objects, there are many ways to define the correlation coefficient, and the Pearson correlation coefficient is the more commonly used one. Correlation tables and correlation diagrams can reflect the relationship between two variables and the direction of their correlation, but they cannot exactly indicate the degree of correlation between the two variables. Correlation coefficient is a statistical indicator used to reflect the close degree of correlation between variables. The correlation coefficient is calculated according to the product difference method. It is also based on the deviation of the two variables from their respective averages, and the degree of correlation between the two variables is reflected by multiplying the two deviations. Definition formula of correlation coefficient:

Define $E[(X-E X)(Y-E X)]$ as the covariance of $(X, Y)$ under two-dimensional random variables, or the covariance of one-dimensional random variables $x$ and $y$, and record it as $\operatorname{cov}(X, Y), \sigma(X, Y)$. 
The correlation coefficient is defined as follows:

$$
\rho(X, Y)=\frac{E[(X-E X)(Y-E X)]}{\sigma(X) \sigma(Y)}
$$

Among them, $E X$ is the mean value of the variable $X, E Y$ is the mean value of the variable $Y, \sigma(X)$ is the variance of $X$, and $\sigma(Y)$ is the variance of $Y$.

Figure 1 shows that when the two variables $X$ and $Y$ follow the same changing law, the correlation coefficient at this time reaches the maximum value of 1 . Figure 2 and Figure 3 show that when there are individual data in the two variables that

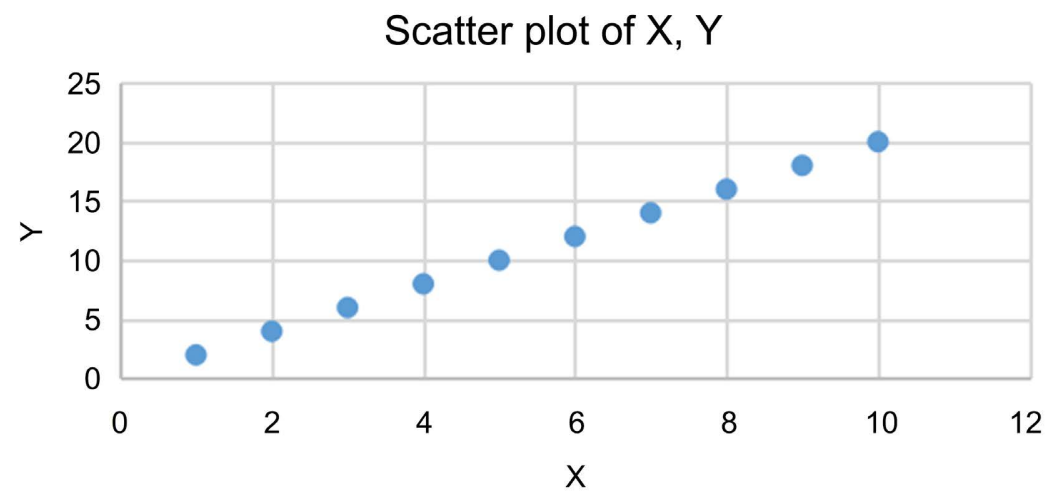

Figure 1. Correlation coefficient 1 of $X, Y$.

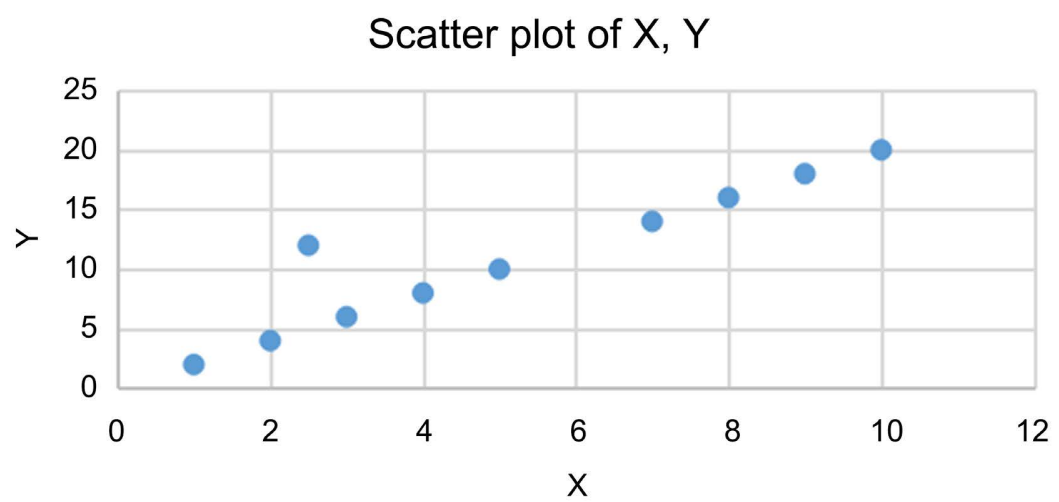

Figure 2. Correlation coefficient 2 of $X, Y$.

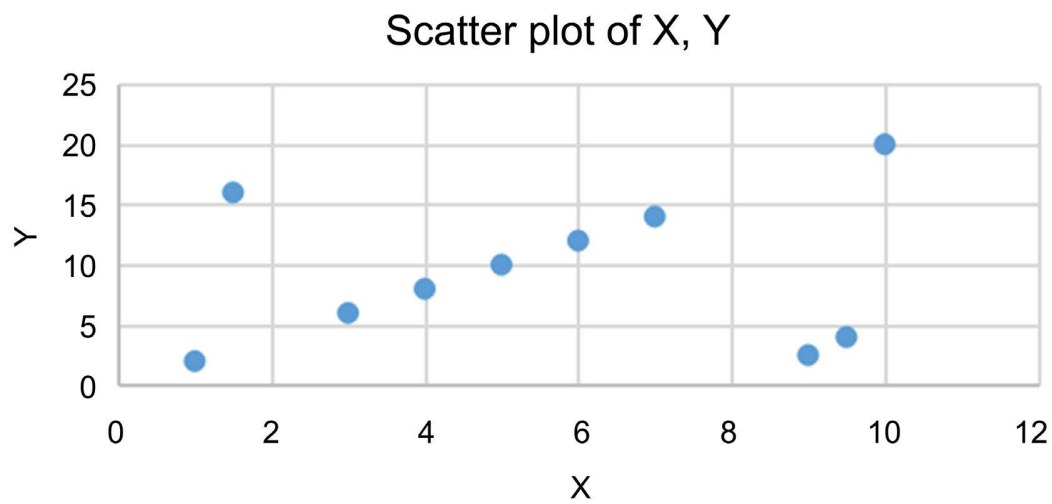

Figure 3. Correlation coefficient 3 of $X, Y$. 
do not follow the changing laws of other data, it may lead to a sharp drop in the correlation coefficient. If the data in the variables $X$ and $Y$ are compared to individuals in society, and the correlation coefficient equal to 1 is compared to the highest goal pursued by a group, the correlation coefficient can be used as an indicator to measure whether the individuals in the group have a collectivist spirit.

\section{Conclusion}

The mission of higher education is to train senior professionals with a sense of social responsibility, innovative spirit and practical ability. From the above analysis, it can be seen that there may be some human factors in mathematical principles. The change of the correlation coefficient is closely related to the trend of the two variables with the change of their mean value. This correlation just reflects the connotation of collectivism. If teachers can skillfully integrate these humanistic spirits in the course of teaching, they can not only increase the vividness of boring mathematics theory classes, but also in natural sciences classrooms, they can subtly improve students' humanistic qualities, and at the same time, they can cultivate students' awareness of rules, discipline, and collectivism, and this teaching method also meets the country's requirements for the cultivation of college students.

\section{Funding}

This paper is supported by Research Foundation of the Nanchang Normal University for Doctors (NSBSJJ2018014). Key R\&D Project of Jiangxi Provincial Department of Science and Technology (20192BBEL50040, 20192BBHL80002).

\section{Conflicts of Interest}

The authors declare no conflicts of interest regarding the publication of this paper.

\section{References}

Boone, C., Meng, C., \& Velden R. (1995). Individualism and Collectivism. Westview Press.

Dillon, K. (2014). Escape from Freedom: Towards the Political Realm. Philosophical Studies in Education, 45, 83-92.

Filliben, J. J. (1975). The Probability Plot Correlation Coefficient Test for Normality. Technometrics, 17, 111-117. https://doi.org/10.1080/00401706.1975.10489279

Mu, Y. S., Liu, X. D., \& Wang, L. D. (2018). A Pearson's Correlation Coefficient Based Decision Tree and Its Parallel Implementation. Information Sciences: An International Journal, 435, 40-58. https://doi.org/10.1016/j.ins.2017.12.059

Oyserman, D., Coon, H. M., \& Kemmelmeier, M. (2002). Rethinking Individualism and Collectivism: Evaluation of Theoretical Assumptions and Meta-Analyses. Psychological Bulletin, 128, 3-72. https://doi.org/10.1037/0033-2909.128.1.3

Robertson, A. (1959). The Sampling Variance of the Genetic Correlation Coefficient. Biometrics, 15, 469-485. https://doi.org/10.2307/2527750

Weiß, C. (2018). Correlation Coefficients. Notfall + Rettungsmedizin, 1-3. 
Xiong, J., Liang, Q., Wan, J. et al. (2018). The Order Statistics Correlation Coefficient and PPMCC Fuse Non-Dimension in Fault Diagnosis of Rotating Petrochemical Unit. IEEE Sensors Journal, 18, 4704-4714. https://doi.org/10.1109/ISEN.2018.2820170

Zhang, Y. M., Wang, C. Y., Li, S. F. et al. (2005). Education and Practice of Introducing Humanistic Spirit in Chemical Engineering and Technology. Chemical Industry and Engineering, No. S1, 108-109.

Zhu, X. (2002). The Modern Library and Traditional Humanistic Spirit. Library and Information Service. 